\title{
Mobilising society to implement solutions for non-communicable diseases
}

\author{
A BMJ series helps map the way towards better health and wellbeing for all
}

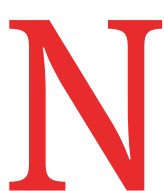

on-communicable diseases (NCDs) constitute a major global health challenge hampering nations' economic growth and sustainable development. Nearly three quarters $(71 \%)$ of allcause mortality worldwide is attributed to NCDs, resulting in 15 million people dying prematurely (between the ages of 30-69 years) each year. ${ }^{1}$ The global burden of NCDs disproportionately affects low and middle income countries, where $75 \%$ of deaths from NCDs and over $85 \%$ of all premature NCD related deaths take place. ${ }^{2}$

The four major groups of NCDs-namely, cardiovascular diseases, cancer, chronic respiratory diseases, and diabetesaccount for over $80 \%$ of all NCD related deaths and share the same four main risk factors: tobacco use, harmful use of alcohol, unhealthy diets, and physical inactivity. Mental health and environmental determinants were recently added to the NCD agenda broadening its scope from four-by-four to five-by-five.

Risk factors for NCDs are influenced by socioeconomic determinants of health that exacerbate health inequalities, with the most vulnerable and marginalised groups hit hardest. Evidence is mounting of substantial human, social, and economic costs from NCDs. A report by the World Economic Forum and the Harvard School of Public Health estimated that cumulative output loss due to cardiovascular disease, chronic respiratory disease, cancer, diabetes and mental health in low and middle income countries will be more than \$47tn (£36tn; €42tn).if national responses are not scaled up between 2011 and 2030. ${ }^{3}$ However, low and middle income countries that implement available cost effective (best buy) interventions immediately will see a return of $\$ 7$ per person by 2030 for every dollar invested. ${ }^{4}$

Recently, there has been a push to accelerate action against the threat of NCDs at both global and national levels. United Nations General Assembly high level meetings on the prevention and control of NCDs in 2011, 2014, and 2018 placed NCDs high on the global health policy agenda and reaffirmed the responsibility of governments to tackle the NCD crisis by developing adequate national multisectoral policy responses. The high level meetings also reiterated the importance of shared accountability by stakeholders across sectors to create an environment conducive to preventing and controlling NCDs. ${ }^{5}$

When heads of state, heads of government, and other high level representatives met in New York in September 2015 to launch the sustainable development goals (SDGs), NCDs (which were not included in the millennium development goals) were recognised as a major barrier to achieving key health related objectives. SDG target 3.4 is a commitment to reduce premature mortality from NCDs by a third by 2030 and enhance mental health and wellbeing. ${ }^{6}$ Other targets related to NCDs include strengthening policies to reduce the harmful use of alcohol, achieving universal health coverage, strengthening implementation of the World Health Organization's Framework Convention on Tobacco Control, supporting research and development of vaccines and medicines for NCDs that primarily affect low and middle income countries, and providing access to affordable essential medicines and vaccines for NCDs. ${ }^{7}$

Despite the growing global interest in NCDs, progress has been insufficient because countries with limited resources struggle with weak health systems and poor national capacities, including technical expertise, research capacity, and surveillance and programme evaluation data. Governments find it particularly difficult to maintain the political momentum generated by UN General Assembly meetings and translate those high level commitments into effective national action, despite the availability of evidence based and cost effective interventions for prevention and control of NCDs. There are many reasons for this, but some of the main challenges are listed in box 1 .

The political landscape for NCDs is entering a critical period globally, but despite implementation challenges we see evidence of renewed political commitments and more buy-in from national governments. This series of articles on NCDs (www.bmj.com/NCDsolutions) represents a timely collaboration between The BMJ and WHO and builds on the gathering momentum for global action. It provides an outlook on the challenges in the prevention and control of NCDs at national, regional, and global levels and highlights the need for multisectoral and multistakeholder policies and for healthin-all and whole-of-society approaches to curb the epidemic. Authors from diverse settings-including policy experts from academia, WHO, other UN agencies, nongovernmental organisations, and business associations-suggest scalable solutions to accelerate the implementation of the commitments made in the three UN General Assembly high level meetings on NCDs.

The articles in this series cover the main issues in prevention and control of NCDs, including financing and partnership building, ${ }^{8}$ integration of NCDs into primary care, ${ }^{9}$ implementation research, social determinants of health, ${ }^{10}$ multisectoral action, nutrition and environmental influences, ${ }^{112}$ a life course approach, ${ }^{13}$ and the development cooperation. It provides a holistic perspective on current challenges

Box 1: Barriers to implementation

- Lack of political will, leadership, commitment, capacity, and action

- Lack of specific policies and costed plans for NCD prevention and control

- Difficulty in priority setting among competing health programmes and adequate and predictable allocation of resources

- Effect of countervailing economic, commercial, and market forces

- Insufficient technical and operational capacity

- Insufficient (domestic and international) financing ${ }^{4}$

- Difficulty of engaging with a highly fragmented and unregulated private sector 


\section{and possible solutions towards meeting the global NCD targets and improving health worldwide by 2030 .}

Competing interests: We have read and understood BMJ policy on declaration of interests and have no interests to declare.

Provenance and peer review: Commissioned; not externally peer reviewed.

This article is part of a series proposed by the WHO Global Coordination Mechanism on NCDs and commissioned by The BMJ, which peer reviewed, edited, and made the decision to publish. Open access fees are funded by the Swiss Agency for Development and Cooperation, International Federation of Pharmaceutical Manufacturers and Associations (IFPMA), UNOPS Defeat-NCD Partnership, Government of the Russian Federation, and WHO.

Svetlana Akselrod, assistant director general ${ }^{1}$ Ashley Bloomfield, director general ${ }^{2}$

Michael Marmot, director ${ }^{3}$

Andrew E Moran, associate professor of medicine ${ }^{4}$ Sania Nishtar, founder ${ }^{5}$

Erika Placella, deputy head ${ }^{6}$

On behalf of the NCD expert editorial group

${ }^{1}$ Non-communicable Diseases and Mental Health, World Health Organization, Geneva, Switzerland

${ }^{2}$ Ministry of Health, New Zealand

${ }^{3}$ Institute of Health Equity, UCL, London, UK

${ }^{4}$ Columbia University, New York, USA

${ }^{5}$ Heartfile, Pakistan
${ }^{6}$ Global Programme Health, Swiss Agency for Development and Cooperation, Bern, Switzerland

Correspondence to: Téa Collins, collinst@who.int

Other members of the NCD editorial expert group for this series are Téa Collins, Thomas Cueni, Mukesh Kapila, Cary Adams, George Alleyne, Katie Dain, Tim Evans, Celina Gorre, Ilona Kickbusch, Colin McIff, Bente Mikkelsen, Ariel Pablos-Mendez, Menno Van Hilten, Naoko Yamamoto

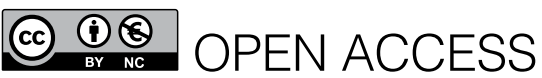

This is an Open Access article distributed under the terms of the Creative Commons Attribution IGO License (https://creativecommons.org/licenses/ by-nc/3.0/igo/), which permits use, distribution, and reproduction for non-commercial purposes in any medium, provided the original work is properly cited.

\section{D) Check for updates}

1 WHO. Factsheet on noncommunicable diseases. https://www.who.int/news-room/fact-sheets/detail/ noncommunicable-diseases

2 WHO. WHO global health estimates 2016: deaths by cause, age, sex, by country and by region, 2000 2016. World Health Organization, 2018

3 Bloom DE, Cafiero ET, Jane-Llopis E, et al. The Global Economic Burden of Non-Communicable Diseases. World Economic Forum, 2011.

4 WHO. Time to deliver: report of the WHO Independent High-Level Commission on Noncommunicable
Diseases. 2018. https://www.who.int/ncds/ management/time-to-deliver/en/

5 UN. Political declaration of the third high-level meeting of the General Assembly on the prevention and control of non-communicable diseases. 2018. http://www.un.org/en/ga/search/view_doc. asp?symbol=A/RES/73/2

6 UN. 2030 agenda for sustainable development. https://www.un.org/sustainabledevelopment/health/

7 WHO. NCD and the sustainable development goals. https://www.who.int/global-coordination-mechanism/ ncd-themes/sustainable-development-goals/en/

8 Bertram M, Banatvala N, Kulikov A, et al. Using economic evidence to support policy decisions to fund interventions for non-communicable diseases. BMJ 2019;365:l1648. doi:10.1136/bmj.l1648

9 Varghese C, Nongkynrih B, Onakpoya I, McCall M, Barkley S, Collins TE. Better health and wellbeing for billion more people: integrating non-communicable diseases in primary care. BMJ 2019;364:1327. doi:10.1136/bmj.1327

10 Marmot M, Bell R. Social determinants and noncommunicable diseases: time for integrated action. BMJ 2019:364:1251. doi:10.1136/bmj.1251

11 Branca F, Lartey A, Oenema S, et al. Transforming the food system to fight non-communicable diseases. BMJ 2019;364:1296. doi:10.1136/bmj.l296

12 Prüss-Ustün A, van Deventer E, Mudu P, et al. Environmental risks and non-communicable diseases. BMJ 2019;364:l265. doi:10.1136/bmj.l265

13 Mikkelsen B, Williams J, Rakovac I, et al. Life course approach to prevention and control of non-communicable diseases. BMJ 2019;364:1257. doi:10.1136/bmj.l257

Cite this as: $B M J$ 2019;365:1360

http://dx.doi.org/10.1136/bmj.1360 